\title{
Anthocyanin Production Using Rough Bluegrass Treated with High-Intensity Light
}

\author{
Dominic P. Petrella ${ }^{1}$ \\ Department of Horticulture and Crop Science, The Ohio State University, \\ 1680 Madison Avenue, Wooster, OH 44691
}

James D. Metzger

Department of Horticulture and Crop Science, The Ohio State University, 2021 Coffey Road, Columbus, OH 43210

Joshua J. Blakeslee

Department of Horticulture and Crop Science, OARDC Metabolite Analysis Center, The Ohio State University, 1680 Madison Avenue, Wooster, OH 44691

\author{
Edward J. Nangle \\ The Ohio State University/Agricultural Technical Institute, 1328 Dover \\ Road, Wooster, $\mathrm{OH} 44691$
}

\section{David S. Gardner \\ Department of Horticulture and Crop Science, The Ohio State University, 2021 Coffey Road, Columbus, OH 43210}

Additional index words. Poa trivialis, light-emitting diode (LED), abiotic stress, flavonoid, dye, nutraceutical

\begin{abstract}
Anthocyanins are plant pigments that are in demand for medicinal and industrial uses. However, anthocyanin production is limited due to the harvest potential of the species currently used as anthocyanin sources. Rough bluegrass (Poa trivialis L.) is a perennial turfgrass known for accumulating anthocyanins, and may have the potential to serve as a source of anthocyanins through artificial light treatments. The objectives of this research were to determine optimal light conditions that favor anthocyanin synthesis in rough bluegrass, and to determine the suitability of rough bluegrass as a source of anthocyanins. When exposed to high-intensity white light, rough bluegrass increased anthocyanin content by 100-fold on average, and anthocyanin contents greater than $0.2 \%$ of dry tissue weight were observed in some samples. Blue light, at intensities between 150 and $250 \mu \mathrm{mol} \cdot \mathrm{m}^{-2} \cdot \mathrm{s}^{-1}$, was the only wavelength that increased anthocyanin content. However, when red light was applied with blue light at $30 \%$ or $50 \%$ of the total light intensity, anthocyanin content was increased compared with blue light alone. Further experiments demonstrated that these results may be potentially due to a combination of photosynthetic and photoreceptor-mediated regulation. Rough bluegrass is an attractive anthocyanin production system, since leaf tissue can be harvested while preserving meristematic tissues that allow new leaves to rapidly grow; thereby allowing multiple harvests in a single growing season and greater anthocyanin yields.
\end{abstract}

Anthocyanins have become sought-after natural products due to potential for medicinal and industrial uses. These metabolites have

Received for publication 19 Apr. 2016. Accepted for publication 20 July 2016

This article is a part of a thesis by senior author in partial fulfillment of the requirements for the $\mathrm{PhD}$ degree at The Ohio State University.

Salaries and research support were provided in part by State and Federal funds appropriated to the Ohio Agricultural Research and Development Center, The Ohio State University. Journal Article HCS-16-10. We thank the James B. and Harriet Beard Graduate Fund. We also thank J.R. Simplot Company for seed used in these experiments.

1Corresponding author. E-mail: petrella.21@osu.edu. a means of large-scale anthocyanin production; however, to date, these techniques have not been able to produce anthocyanins at levels sufficient to meet current industrial needs (Delgado-Vargas, 2000; Vogelien et al., 1990; Yamamoto and Mizuguchi, 1982). One way to meet the increasing demand for anthocyanins is to employ nonconventional plant species, such as poaceous grasses. The anatomy and perennial nature of turfgrasses make them attractive anthocyanin production systems.

Turfgrasses accumulate anthocyanins in leaves that originate from meristematic tissues that sit at or below the soil surface (Christians, 2011). Leaf tissue can therefore be harvested while keeping meristematic tissues intact, allowing for year-round production from the same stand of plants. Cool-season turfgrasses $\left(\mathrm{C}_{3}\right.$ photosynthetic) devote greater than $60 \%$ of photosynthate toward leaf and sheath growth, and the potential yield of anthocyanin-containing tissue could be upwards of $3 \mathrm{Mg} \cdot \mathrm{ha}^{-1}$ after a single harvest (Krans and Beard, 1980; Landschoot and Waddington, 1987; Younger, 1969). Relative to fruit crops, currently the most used anthocyanin source, turfgrasses provide numerous advantages. For example, turfgrasses could be harvested for anthocyanins within weeks of seeding, and leaf tissue could be harvested at least once per month. Further, since turfgrasses do not undergo secondary growth, a greater proportion of photosynthate could be devoted toward anthocyanin synthesis.

Rough bluegrass ( $P$. trivialis L.) is known to constitutively produce the anthocyanins cyanidin-3-glucoside and cyanidin-3malonylglucoside in the leaf sheath (Fossen et al., 2002; Hurley, 2010). This turfgrass is a fast-growing perennial under field conditions, and high tissue yield could therefore be expected (Atkin et al., 1996). Still, to employ this species as an industrial crop, it would be necessary to increase anthocyanin production in rough bluegrass to levels greater than those currently observed in the field. Environmental stress, light in particular, is one factor that is known to increase anthocyanin synthesis (Boldt et al., 2014).

Transient anthocyanin accumulation occurs with changes in light quantity and/or quality, and has been documented in a variety of plants including: tomato, Arabidopsis, maize, sorghum, rye, red cabbage, and mustard (Chalker-Scott, 1999; Mancinelli, 1985; Mol et al., 1996). Light is a requirement for anthocyanin synthesis, and anthocyanin production is photoregulated (Downs and Siegelman, 1963; Lange et al., 1971; Mancinelli, 1985; Rabino et al., 1977; Vyas et al., 2014). Photomanipulation could therefore be used to increase anthocyanin content in rough bluegrass.

Phytochrome has been shown to regulate anthocyanin synthesis through the absorption of red or far-red (FR) light (Kerckhoffs and Kendrick, 1997; Mancinelli, 1985; Neff and Chory, 1998; Oh et al., 2014; Wade et al., 
2001). However, blue light also regulates anthocyanin synthesis, although this is accomplished through the activity of multiple photoreceptors, including both cryptochromes and phototropins (Galvão and Frankhauser, 2015). Cryptochromes are well known to regulate anthocyanin synthesis, whereas phototropins have only been recently implicated in anthocyanin regulation (Folta and Carvalho, 2015; Fox et al., 2012; Hong et al., 2009; Kadomura-Ishikawa et al., 2013; Poppe et al., 1998; Vandenbussche et al., 2007).

Treatment with red and blue light may also increase anthocyanin synthesis through photoreceptor coaction. In other words, red light may be noninductive on its own, but when applied with blue light, anthocyanin synthesis may be increased compared with blue light alone (Drumm and Mohr, 1978; Mancinelli, 1985; Mohr and Drumm-Herrel, 1983; Wade et al., 2001). In addition, anthocyanin synthesis has also been shown to be regulated through photosynthesis and increased under high-intensity light (Kumar Das et al., 2011; Mancinelli et al., 1976; Mancinelli and Rabino, 1978; Mancinelli, 1985; Schneider and Stimson, 1971; Weiss and Halevy, 1991). Therefore, anthocyanin content may increase through a combination of photosynthetic and photoreceptor-mediated regulation when blue, red, and/or combinations of blue and red light are applied.

Given the previously established regulation of anthocyanin synthesis in several monocot crops (i.e., sorghum and maize), we hypothesized that anthocyanin production in rough bluegrass could be manipulated through exposure to specific light regimes. The objectives of this research were to determine conditions that favor anthocyanin synthesis in rough bluegrass by first evaluating whether treatment with high-intensity light could increase anthocyanin content. Second, the wavelength(s) of light capable of upregulating anthocyanin synthesis was determined to optimize light conditions. Finally, the role of photosynthesis on anthocyanin production in rough bluegrass was evaluated.

\section{Materials and Methods}

Metal halide lighting. Phillips advance high-intensity discharge $400 \mathrm{~W}$ ballasts were used for full-spectrum lighting experiments, along with metal halide (400 W) lamps (Phillips Advance ${ }^{\circledR}$, Rosemont, IL). For growth chamber experiments, ballasts were kept outside of the growth chamber, and wiring was passed through front-mounted instrument ports to allow for lamp mounting inside of the growth chamber. Light intensity was measured using a LI-COR quantum sensor and LI-2189 light meter (LI-COR ${ }^{\circledR}$ Biosciences, Lincoln, NE).

Light-emitting diode array construction. Blue and red 5050 light-emitting diodes (LEDs) $(5.0 \times 5.0 \mathrm{~mm})$ were purchased premounted on flexible metal-core printed circuit strips - 60 LED s.m ${ }^{-1}$ (Torchstar Inc. ${ }^{\circledR}$, La Puente, CA). LED strips were cut into lengths of $40 \mathrm{~cm}$ and were attached side by side to sheets of cardboard $(150 \times 60 \times 0.64$ $\mathrm{cm})$ using $3 \mathrm{M}^{\circledR} 8805$ thermally conductive tape $\left(3 \mathrm{M}^{\circledR}\right.$, Medina, OH). LED strips were wired in parallel, and were powered using a $12 \mathrm{~V}$ AC-DC switching power supply (LED Wholesalers $^{\circledR}$, Hayward, CA). For experiments combining red and blue light, LED strips were wired to separate dimming units (LED Wholesalers ${ }^{\circledR}$, Hayward, CA) to allow for adjustment in spectral quality.

High-power, 10-W FR LEDs (LED Engin ${ }^{\circledR}$ Inc., San Jose, CA) were mounted on aluminum sheet metal $(150 \times 60 \times 0.16 \mathrm{~cm})$ using thermally conductive tape. Four FR LEDs were wired in parallel with a $15-\mathrm{W} 4.7-\Omega$ wire-wound cement-filled resistor (Xicon ${ }^{\circledR}$ Passive Components, Arlington, TX) soldered in between each negative terminal. Lenses were attached to individual LEDs (LED Engin ${ }^{\circledR}$ High Uniformity Lighting Lens) using thermal adhesive (Arctic Silver $^{\circledR}$ Inc. Visalia, CA). Four groups of parallel wired FR LEDs (16 total LEDs) were used for each array, and each group was powered using an AC-DC switching power supply. LED arrays for all experiments were constructed in three replicates. LED arrays were mounted within Conviron E15 growth chambers set to $15^{\circ} \mathrm{C}$ (Controlled Environment Ltd., Winnipeg, Canada) by hanging them underneath a pre-existing adjustable light rack. Ventilation fans, that provided a flow rate of $425 \mathrm{~m}^{3} \cdot \mathrm{h}^{-1}$ or greater, were placed on top of the light rack and provided a constant flow of air over the LED arrays.

Light measurement. LED array spectral distribution and quantum flux were measured using a Stellarnet ${ }^{\circledR}$ BLACK-Comet spectroradiometer, a CR2 cosine receptor, and spectra were analyzed using SpectraWiz ${ }^{\circledR}$ software (Stellarnet $^{\circledR}$ Inc., Tampa, FL). Blue LEDs produced a bandwidth of $400-525 \mathrm{~nm}$ with a peak wavelength of $453 \mathrm{~nm}$ (3.38\% of the spectrum). Red LEDs produced a bandwidth of $550-700 \mathrm{~nm}$ with a peak wavelength of $635 \mathrm{~nm}(4.61 \%$ of the spectrum). FR LEDs produced a bandwidth of $670-800 \mathrm{~nm}$ with a peak wavelength of $732 \mathrm{~nm}(3.13 \%$ of the spectrum).

Light intensity was controlled through LED dimming, and by adjusting the distance between the plant canopy and the LED array. When light intensity and distance were set, canopy temperature was measured using a Kestrel 3000 weather meter (Kestrel Meters, Birmingham, MI). On average, the canopy temperatures under an LED array consisting of $100 \%$ red light were $20.5 \pm$ $2.7{ }^{\circ} \mathrm{C}$; under $100 \%$ blue light, they were $20.6{ }^{\circ} \mathrm{C} \pm 2.5{ }^{\circ} \mathrm{C}$; and under dichromatic arrays (i.e., $50 \%$ red and blue light), they were $20.4{ }^{\circ} \mathrm{C} \pm 2.5{ }^{\circ} \mathrm{C}$ (not statistically different when compared using Student's $t$ test; $P=0.05$ ).

Plant materials and growth conditions. Rough bluegrass, cv. Havana (J.R. Simplot Company, Boise, ID), plants were grown in $2.5 \times 12 \mathrm{~cm}$ Cone-tainers ${ }^{\mathrm{TM}}$ (Stuewe and Sons, Tangent, OR) using soilless media (Farfard $^{\circledR}$ 3B Mix, Sungro ${ }^{\circledR}$ Horticulture,
Agawam, MA). However, for experiment 1, plants were grown to maturity $(\approx 3$ months old) in standard $15 \times 11 \mathrm{~cm}$ plastic pots using a seeding rate of $1.8 \mathrm{~kg}$ (seed) $/ 93 \mathrm{~m}^{2}$ according to the methods of Nangle et al. (2015). Mature plants used in experiments other than experiment 1 were grown under greenhouse conditions, and were maintained as single plants (tillers removed) per Cone-tainer ${ }^{\mathrm{TM}}$ rather than a stand of multiple plants. Seedlings $7 \mathrm{~d}$ past germination (DPG) were also used in experiments 2-5. Light-grown seedlings were grown within a Conviron E15 growth chamber: 12 -h photoperiod, $200 \mu \mathrm{mol} \cdot \mathrm{m}^{-2} \cdot \mathrm{s}^{-1}$, and $20{ }^{\circ} \mathrm{C}$ day/night temperature. Plants were watered daily, and were not fertilized. Darkgrown seedlings were also grown under the same growth chamber conditions by placing Cone-tainers ${ }^{\mathrm{TM}}$ under four layers of black polyester cloth. Dark conditions were verified using a LI-COR quantum sensor and LI-2189 light meter. Two to three seedlings were grown per Cone-tainer ${ }^{\mathrm{T} M}$.

Pigment extractions and analysis. Chlorophylls were extracted using N,Ndimethylformamide, analyzed, and spectrophotometrically quantified (Shimadzu UV1800 spectrophotometer, Shimadzu Corp., Colombia, MD) according to the methods of Wellburn (1994). Total anthocyanins were extracted using $1 \%$ acidified methanol $(\mathrm{HCl})$. Fresh shoot tissue was weighed and extracted in $10 \mathrm{~mL}$ of extraction solvent for $24 \mathrm{~h}$ in the dark at $4{ }^{\circ} \mathrm{C}$ (Rabino and Mancinelli, 1986). Aliquots were analyzed spectrophotometrically, and relative anthocyanin content was estimated using the following equation: $\left(\begin{array}{lll}\mathrm{Abs}_{530} & -0.25 \mathrm{Abs}_{657}\end{array}\right) / \mathrm{g}$ fresh weight (FW) (Rabino and Mancinelli, 1986). Cyanidin-3-glucoside equivalents were determined using the $\mathrm{pH}$ differential method (Giusti and Wrolstad, 2001). Tissue extracts for the $\mathrm{pH}$ differential method were prepared as previously described (Nangle et al., 2015).

Anthocyanins were extracted and isolated for liquid chromatography-mass spectrometry (LC-MS) as previously described (Nangle et al., 2015). Aliquots of rough bluegrass extract were saponified to determine whether anthocyanins present were acylated using previously described methods (de PascualTeresa et al., 2002). Purple corn was used as a standard based on previously identified anthocyanins (de Pascual-Teresa et al., 2002). The following method was used for anthocyanin identification. A Shimadzu 2010EV LC-ESI MS coupled with a Shimadzu SPD-M20A photodiode array was used to identify anthocyanins. A Varian C18-A $(150 \mathrm{~mm} \times 4.6 \mathrm{~mm}$ I.D. $)$ column was used (Varian Inc., Lake Forest, CA). A binary flow mobile phase consisting of a) $4.5 \%$ aqueous formic acid and b) $100 \%$ acetonitrile with a flow rate of $0.8 \mathrm{~mL} \cdot \mathrm{min}^{-1}$ was used, and $20 \mu \mathrm{L}$ of sample was injected onto the column. Anthocyanins were separated using the following gradient: $12 \% \mathrm{~B} 1-25 \mathrm{~min}$, $35 \%$ B $25-30$ min, a $35 \%$ to $12 \%$ decrease in B from 30 to $38 \mathrm{~min}$, and $12 \% \mathrm{~B}$ until minute 45 . 
Ultraviolet-vis spectral profiles, retention times, and mass spectra were compared with those previously published for anthocyanin identification (de Pascual-Teresa et al., 2002; Giusti and Wrolstad, 2001; Nangle et al., 2015).

Experimental design, setup, and statistics. Five separate experiments were performed to determine the role of light in upregulating anthocyanin content in rough bluegrass. Experiment 1 was designed to evaluate whether high-intensity white light could increase anthocyanin content in a rough bluegrass. Six pots of mature rough bluegrass $[15 \times$ $\left.11 \mathrm{~cm}-\left(1.8 \mathrm{~kg} \mathrm{seed} / 93 \mathrm{~m}^{2}\right)\right]$ were constantly exposed to $1000 \mu \mathrm{mol} \cdot \mathrm{m}^{-2} \cdot \mathrm{s}^{-1}$ of light from two 400-W metal halide lamps placed $61 \mathrm{~cm}$ above the plant canopy for $5 \mathrm{~d}$. After treatment, leaf tissue was harvested down to the crown of the plant, and analyzed for cyanidin3 -glucoside equivalents. All pots of rough bluegrass were then transferred back to the greenhouse, and leaves were regrown to $3 \mathrm{~cm}$. Rough bluegrass plants were then treated under high-light conditions again for replication over time, and to simulate a potential production system. Using these methods, experiment 1 was replicated three times in total. For a given replicate, the six rough bluegrass samples treated were extracted and analyzed separately, and the resulting cyanidin-3glucoside equivalents were averaged for statistical analysis. A growth chamber was used for high-light treatment in this experiment, and the experiment was rotated to a new growth chamber for each replicate. Plants grown under high light were compared with untreated plants that were grown under standard greenhouse conditions.

Experiment 2 was designed to determine which wavelengths of light were able to upregulate anthocyanin production. Light- and dark-grown seedlings (7 DPG) were exposed to either $200 \mu \mathrm{mol} \cdot \mathrm{m}^{-2} \cdot \mathrm{s}^{-1}$ blue, red, or FR LED light constantly for 5 d. Dark-grown seedlings were used as an added treatment alongside light-grown seedlings because tissues exhibiting lower quantities of chlorophyll $a$ and $b$ may exhibit different patterns of anthocyanin accumulation (Hughes et al., 2007). In experiment 3, an anthocyanin dose response curve was generated using a range of blue light intensities. Light-grown seedlings (7 DPG) were constantly exposed to $5 \mathrm{~d}$ of the following blue LED light treatments: 25, 50, 100, 150, 200, 250,300 , and $350 \mu \mathrm{mol} \cdot \mathrm{m}^{-2} \cdot \mathrm{s}^{-1}$ of blue light. Experiment 4 was designed to evaluate coaction between blue and red light by altering spectral quality. Mature (3-month old) and light-grown seedlings (7 DPG) were treated for $5 \mathrm{~d}$ with $200 \mu \mathrm{mol} \cdot \mathrm{m}^{-2} \cdot \mathrm{s}^{-1}$ of constant LED light consisting of the following blue/ red spectral distributions: $0 \%$ blue $(100 \%$ red), $30 \%$ blue $(70 \%$ red), $50 \%$ blue $(50 \%$ red), $70 \%$ blue $(30 \%$ red), or $100 \%$ blue ( $0 \%$ red)

Experiment 5 was designed to evaluate the effects of photosynthesis on anthocyanin synthesis by altering spectral distribution, light intensity, and photosynthetic depression using the photosystem II inhibitor amicarbazone [4-amino-N-(tertbutyl)-3-isopropyl-5-oxo-4,5-dihydro-1H-1,2,4triazole-1-carboxamide]. Amicarbazone was applied at a concentration of $2.8 \mathrm{mg} \cdot \mathrm{L}^{-1} \mathrm{using}$ the commercially available product Xonerate (70\% amicarbazone by weight, Arysta LifeScience $^{\odot}$, Cary, NC) $4 \mathrm{~h}$ before light treatment using an atomizing spray applicator (Dayan et al., 2009). Light- and dark-grown seedlings (7 DPG) were treated for $5 \mathrm{~d}$ with $170 \mu \mathrm{mol} \cdot \mathrm{m}^{-2} \cdot \mathrm{s}^{-1}$ blue light plus $0,10,25,50$, or $100 \mu \mathrm{mol} \cdot \mathrm{m}^{-2} \cdot \mathrm{s}^{-1}$ red light using dimmable LED arrays. The experiment was also performed in reverse using $170 \mu \mathrm{mol} \cdot \mathrm{m}^{2} \cdot \mathrm{s}^{-1}$ red light plus $0,10,25,50$, or $100 \mu \mathrm{mol} \cdot \mathrm{m}^{-2} \cdot \mathrm{s}^{-1}$ blue light. Experiments $2-5$ had a total of six plant samples per treatment that were pooled for analysis.

Plants were dark adapted for $24 \mathrm{~h}$ before light treatments, and were watered daily. Growth chamber doors were open on average for $5 \mathrm{~min} /$ day, and light intensity outside of the growth chamber was $\approx 3 \mu \mathrm{mol} \cdot \mathrm{m}^{-2} \cdot \mathrm{s}^{-1}$. For experiments using more than one LED array treatment, LED arrays were separated in each growth chamber using cardboard sheets covered in aluminum foil. Spectroradiometeric measurements were taken before and after the separation sheet was installed to verify that light from neighboring treatments was not being transmitted or interfering. All experiments were analyzed as randomized complete block designs with three replicates. Separate Conviron E15 growth chambers served as blocking units, and three separate chambers were used simultaneously for experiments other than experiment 1 (replicated over time). All statistics were performed using Minitab software v. 17. Data were analyzed using General Linear Model ANOVA (GLM ANOVA), and Tukey's honest significant difference test was used for mean separation $(P=0.05)$.

\section{Results}

Anthocyanin upregulation under highintensity white light. When exposed to constant high-intensity white light $\left(1000 \mu \mathrm{mol} \cdot \mathrm{m}^{-2} \cdot \mathrm{s}^{-1}\right.$ metal halide lighting), rough bluegrass plants significantly increased anthocyanin concentration compared with untreated plants (Table 1). In untreated plants, the low levels of anthocyanins present were localized primarily to sheath tissue, a trend similar to what has been previously observed in field-grown rough bluegrass (Hurley, 2010). Lighttreated plants, however, exhibited an average 117.64-fold increase in anthocyanin content, and accumulated anthocyanins in both leaf blades and sheath tissue (Table 1).
These increases were independent of the growth stage of the tissue, and were observed in plants of all ages and developmental stages within the stand. Anthocyanins were identified via LC-MS, and the presence of cyanidin-3-glucoside and cyanidin3-malonylglucoside were confirmed based on comparison of mass fragmentation data (Table 1), retention times, and ultravioletvis spectral profiles (Fig. 1) to a purple corn standard containing both cyanidin-3glucoside and cyanidin-3-malonylglucoside, as well as comparison with previously published retention times and spectral profiles for turfgrasses (de Pascual-Teresa et al., 2002; Nangle et al., 2015). In rough bluegrass tissue, cyanidin-3-glucoside accounted for $12.7 \%$ of the total peak area (ultraviolet-vis $520 \mathrm{~nm}$ ) and cyanidin-3-malonylglucoside accounted for $89.3 \%$ of the total peak area (Table 2). To further confirm the presence of cyanidin-3-malonylglucoside, the acyl group was removed through saponification, and the corresponding release of cyanidin-3glucoside was measured using LC-MS (Fig. 1). Comparing chromatograms of rough bluegrass, saponified rough bluegrass, and purple corn confirmed mass spectrometry results through compound retention time (Fig. 1A-C). Ultraviolet-vis spectral profiles of both cyanidin-3-glucoside and cyanidin-3malonylglucoside from rough bluegrass and purple corn also exhibited the same spectral profiles and maxima (Fig. 1D-G).

Wavelength specificity. To determine the primary wavelength(s) of light responsible for upregulating anthocyanin synthesis in rough bluegrass, dark-grown and lightgrown rough bluegrass seedlings were exposed to blue, red, and FR LED light. Analysis of chlorophyll content showed that seedlings grown under dark conditions had significantly lower concentrations of chlorophyll a, whereas chlorophyll b content was not different between light- and dark-grown seedlings (Fig. 2A). These results are reflected in the chlorophyll a:b ratios calculated for light- and dark-grown seedlings. Darkgrown seedlings had a significantly lower chlorophyll a:b ratio compared with lightgrown seedlings (Fig. 2B).

When exposed to $200 \mu \mathrm{mol} \cdot \mathrm{m}^{-2} \cdot \mathrm{s}^{-1}$ of blue, FR, and red LED light, only blue light increased anthocyanin content in light-grown seedlings (Fig. 2C). Likewise, dark-grown seedlings only showed a significant increase in anthocyanin content when exposed to blue light (Fig. 2D). For both dark-grown and light-grown seedlings, anthocyanins visually accumulated in mesocotyl, sheath, and leaf tissues. Interestingly, in dark-grown

Table 1. Anthocyanin concentration (cyanidin-3-glucoside eq.) of rough bluegrass after light treatment.

\begin{tabular}{lcc}
\hline Light treatment & $\begin{array}{c}\text { Cyanidin-3-glucoside } \\
\text { eq. }(\mathrm{mg} / 100 \mathrm{~g} \mathrm{DW})\end{array}$ & $\begin{array}{c}\text { Avg. fold } \\
\text { difference }\end{array}$ \\
\hline Untreated & $1.32 \pm 0.64^{\mathrm{z}}$ & N/A \\
HID metal halide & $155.14 \pm 88.45^{* * * y}$ & $117.64 \pm 67.07$ \\
\hline
\end{tabular}

HID metal halide $155.14 \pm 88.45 * * * y$ $17.64 \pm 67.07$

$\mathrm{DW}=$ dry weight $\mathrm{HID}=$ high-intensity discharge

$*, * *, * * *$ Nonsignificant or significant at $P \leq 0.05,0.01$, or 0.001 , respectively.

${ }^{\mathrm{z}}$ Mean \pm SD $(\mathrm{n}=3)$

${ }^{\mathrm{y}}$ Statistical significance $(P=0.05)$ determined using a 2 -sample $t$ test. 
seedlings, a majority of pigmentation was concentrated in the mesocotyl region, a trend that was not observed in light-grown seedlings.

Blue light dose response. Light-grown seedlings were treated with blue LED light ranging in intensity from 25 to 350 $\mu \mathrm{mol} \cdot \mathrm{m}^{-2} \cdot \mathrm{s}^{-1}$, and results showed that anthocyanins did not begin to accumulate in high quantities until plants were exposed to 150 $\mu \mathrm{mol} \cdot \mathrm{m}^{-2} \cdot \mathrm{s}^{-1}$ blue light (Fig. 3). We determined that the threshold blue light intensity needed to stimulate anthocyanin synthesis in rough bluegrass lies somewhere between 150 and 250 $\mu \mathrm{mol} \cdot \mathrm{m}^{-2} \cdot \mathrm{s}^{-1}$. Levels of anthocyanin observed after exposure to $150 \mu \mathrm{mol} \cdot \mathrm{m}^{-2} \cdot \mathrm{s}^{-1}$ of blue light were not statistically different from those observed at 100 or $200 \mu \mathrm{mol} \cdot \mathrm{m}^{-2} \cdot \mathrm{s}^{-1}$. Further, anthocyanin levels at $200 \mu \mathrm{mol} \cdot \mathrm{m}^{-2} \cdot \mathrm{s}^{-1}$ were not statistically different from those seen at $250 \mu \mathrm{mol} \cdot \mathrm{m}^{-2} \cdot \mathrm{s}^{-1}$. Taken together, these data indicate that anthocyanin production is stimulated at blue light intensities between 150 and $250 \mu \mathrm{mol} \cdot \mathrm{m}^{-2} \cdot \mathrm{s}^{-1}$. Our data also indicate that the response begins to saturate above $250 \mu \mathrm{mol} \cdot \mathrm{m}^{-2} \cdot \mathrm{s}^{-1}$ of blue light (Fig. 3).

Coaction between blue and red light. To determine whether red light could modulate the blue light response, light-grown seedlings were exposed to $200 \mu \mathrm{mol} \cdot \mathrm{m}^{-2} \cdot \mathrm{s}^{-1}$ LED light treatments consisting of $0 \%$ blue (100\% red), $30 \%$ blue ( $70 \%$ red), $50 \%$ blue (50\% red), $70 \%$ blue ( $30 \%$ red), or $100 \%$ blue $(0 \%$ red). Applications of blue and red light together increased anthocyanin synthesis compared with blue light alone (Fig. 4). Specifically, the addition of $30 \%$ or $50 \%$ red light significantly increased anthocyanin content compared with $100 \%$ blue light in light-grown seedlings (Fig. 4A). Experiments were repeated using mature rough bluegrass plants (3-month old), and the results showed a similar trend. In the case of mature plants, however, only the addition of $30 \%$ red light increased anthocyanin content compared with $100 \%$ blue light (Fig. 4B).

Photosynthetic contribution to anthocyanin synthesis. Dark-grown and light-grown seedlings were exposed to LED light treatments with a fixed quantity of blue light (170 $\left.\mu \mathrm{mol} \cdot \mathrm{m}^{-2} \cdot \mathrm{s}^{-1}\right)$ and increasing quantities of red light $\left(0,10,25,50\right.$, or $\left.100 \mu \mathrm{mol} \cdot \mathrm{m}^{-2} \cdot \mathrm{s}^{-1}\right)$. A subset of rough bluegrass seedlings were also treated with the photosystem II inhibitor amicarbazone. For light-grown seedlings, anthocyanin content increased as the quantity of red light increased (Fig. 5A). The addition of $100 \mu \mathrm{mol} \cdot \mathrm{m}^{-2} \cdot \mathrm{s}^{-1}$ of red light led to a significant increase in anthocyanin concentration compared with all other treatments, suggesting that the response may be due to an increase in photosynthesis rather than the involvement of phytochrome. When light-grown plants were treated with amicarbazone, anthocyanin synthesis saturated at $25 \mu \mathrm{mol} \cdot \mathrm{m}^{-2} \cdot \mathrm{s}^{-1}$, supporting a potential role for red light in increasing anthocyanin content through photosynthesis (Fig. 5B).

Results for dark-grown seedlings showed a similar trend to those observed in light-grown seedlings. Anthocyanin content increased in a linear fashion with increasing red light intensity, and the addition of $100 \mu \mathrm{mol} \cdot \mathrm{m}^{-2} \cdot \mathrm{s}^{-1}$ led to a significant increase in anthocyanin

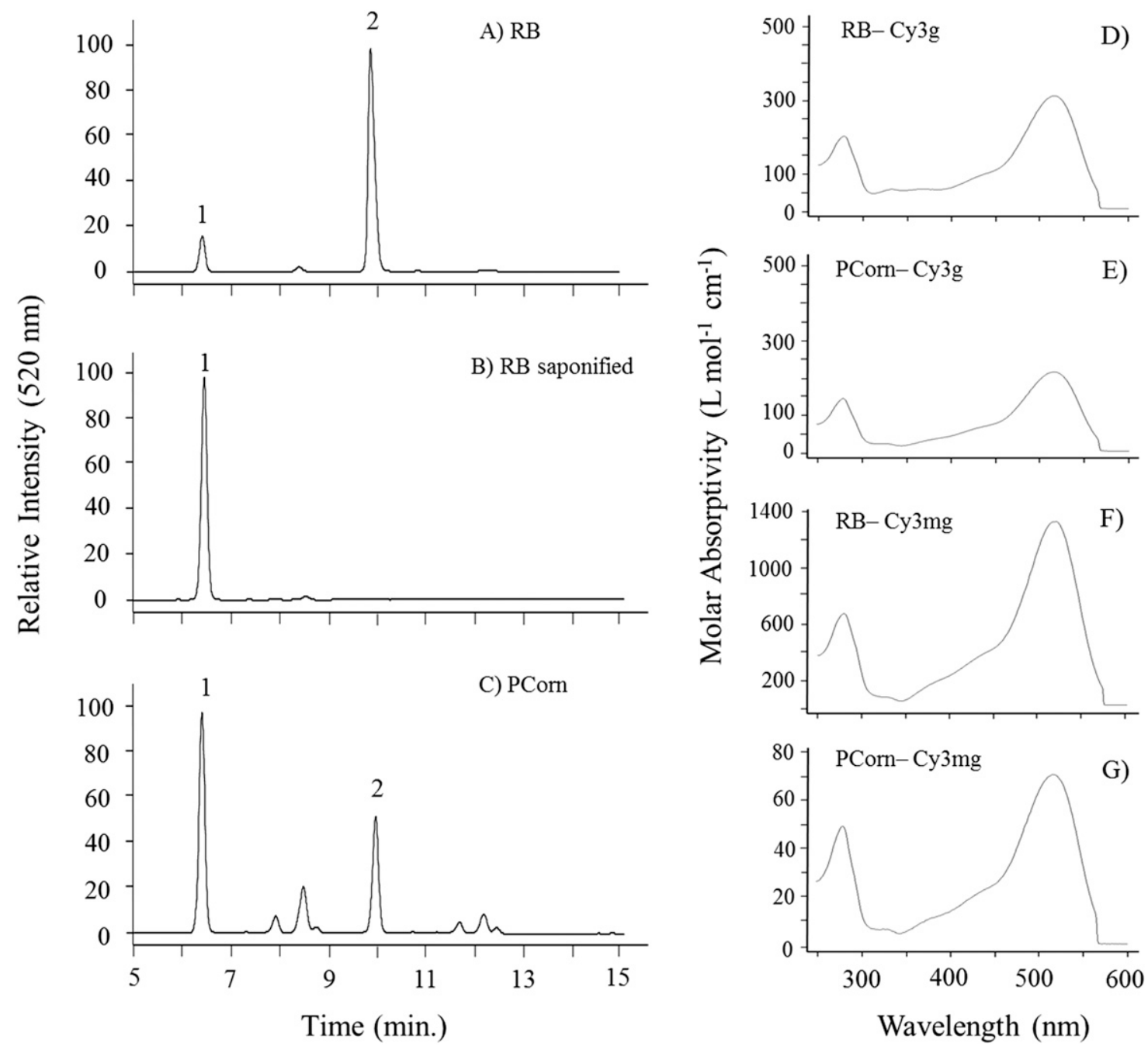

Fig. 1. High-performance liquid chromatography chromatograms of rough bluegrass (RB); cyanidin-3-glucoside; Cy3g (1), and cyanidin-3-malyonlyglucoside; Cy3mg (2). (A) RB anthocyanins; (B) saponified RB anthocyanins; and (C) purple corn (PCorn) anthocyanins. Sample saponification was used to confirm the presence of cyanidin-3-malyonylglucoside, and retention times were compared with PCorn as a standard. Ultraviolet-vis spectral profiles were also used to confirm anthocyanin identity (D-G). Spectral profiles of cyanidin-3-glucoside from (D) RB and (E) PCorn exhibited the same profile and maxima (279 and $517 \mathrm{~nm}$ ). Spectral profiles of cyanidin-3-malonylglucoside from (F) RB and (G) PCorn exhibited the same profile and maxima (279 and $519 \mathrm{~nm})$. Anthocyanins were identified using mass spectrometry data (Table 2) along with retention times and ultraviolet-vis absorption spectral profiles. 
Table 2. Liquid chromatography-mass spectrometry identification of anthocyanins accumulated in rough bluegrass after light treatment.

\begin{tabular}{|c|c|c|c|c|c|c|}
\hline Peak & $\mathrm{T}_{\mathrm{r}}(\min )^{\mathrm{z}}$ & $(\mathrm{M})^{+\mathrm{y}}$ & Mass fragment ${ }^{\mathrm{x}}$ & Ultraviolet-vis $(\mathrm{nm})^{\mathrm{w}}$ & Percent of peak area $(520 \mathrm{~nm})^{\mathrm{v}}$ & Peak identity \\
\hline 1 & 6.41 & 449 & 287 & 279,517 & $12.7 \%$ & Cyanidin-3-glucoside \\
\hline 2 & 9.86 & 535 & 287 & 279,519 & $89.3 \%$ & Cyanidin-3-malonyl glucoside \\
\hline
\end{tabular}

Retention time.

${ }^{\mathrm{y}}$ Molecular ion.

${ }^{\mathrm{x}}$ Aglycone fragment.

${ }^{\text {w}}$ Peak absorption of compounds in ultraviolet and PAR regions.

vercentage of anthocyanin identified based on peak area of ultraviolet-vis $(520 \mathrm{~nm})$ chromatogram.
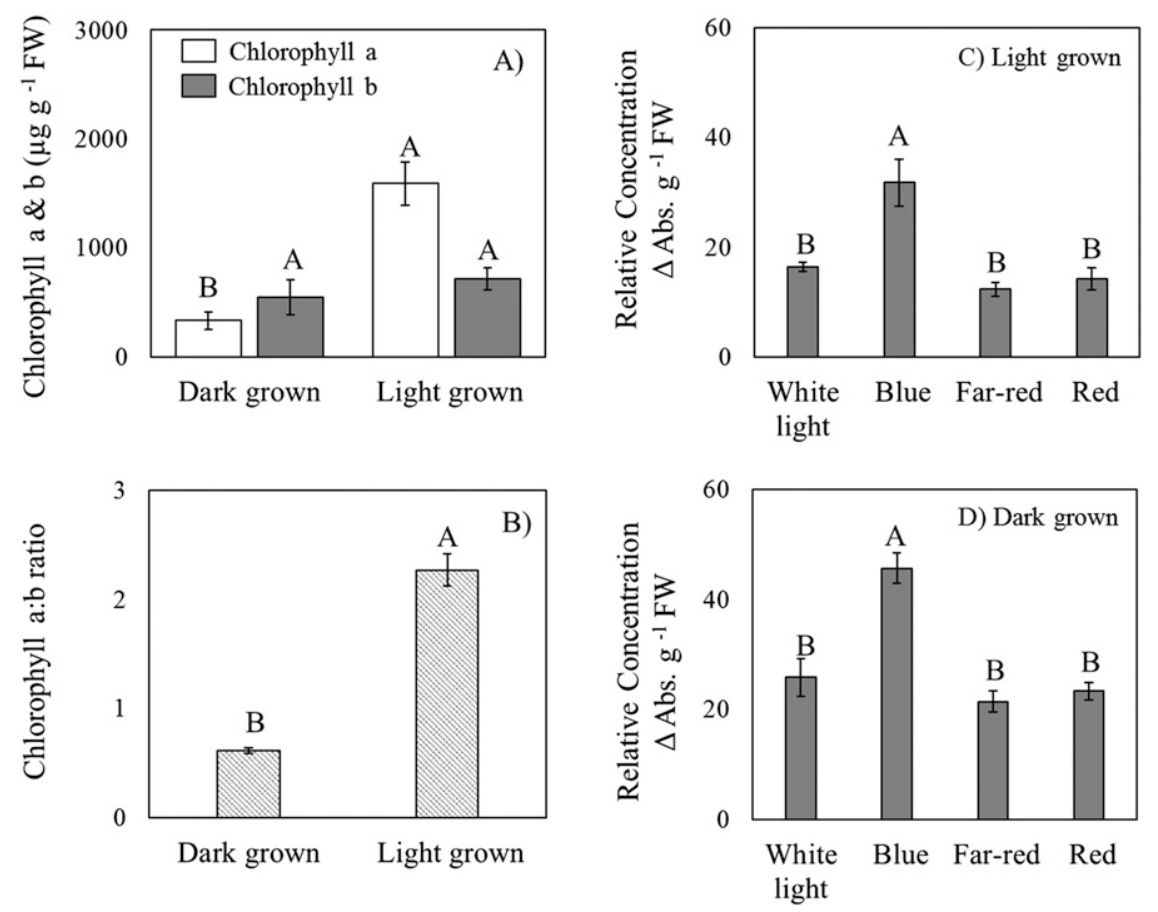

Fig. 2. (A) Chlorophyll a and b content, and (B) chlorophyll a:b ratios of dark- and light-grown rough bluegrass $(\mathrm{RB})$ seedlings. Relative anthocyanin concentration of $(\mathbf{C})$ light-grown and (D) dark-grown RB seedlings treated with a white light (control), blue, far-red, or red light-emitting diode light (200 $\left.\mu \mathrm{mol} \cdot \mathrm{m}^{-2} \cdot \mathrm{s}^{-1}\right)$. Relative anthocyanin concentration $=\left(\mathrm{Abs}_{530}-0.25 \mathrm{Abs}_{657}\right) / \mathrm{g}$ fresh weight. Error bars represent treatment SE, and letters represent mean separation using Tukey's honest significant difference $(\mathrm{n}=3)$. Different letters indicate a significant statistical difference $(P=0.05)$.

concentration compared with 0,10 , and 25 $\mu \mathrm{mol} \cdot \mathrm{m}^{-2} \cdot \mathrm{s}^{-1}$ red light treatments (Fig. 5C). After treatment with amicarbazone, anthocyanin content saturated at $25 \mu \mathrm{mol} \cdot \mathrm{m}^{-2} \cdot \mathrm{s}^{-1}$ and exhibited a sharp decline with increasing quantities of red light, again suggesting photosynthetic regulation (Fig. 5D).

In reverse experiments, when seedlings were exposed to a fixed amount of red light $\left(170 \mu \mathrm{mol} \cdot \mathrm{m}^{-2} \cdot \mathrm{s}^{-1}\right)$ and increasing blue light $\left(0,10,25,50,100 \mu \mathrm{mol} \cdot \mathrm{m}^{-2} \cdot \mathrm{s}^{-1}\right)$, light-grown seedlings only increased anthocyanin synthesis when exposed to an additional 100 $\mu \mathrm{mol} \cdot \mathrm{m}^{-2} \cdot \mathrm{s}^{-1}$ of blue light (Fig. 6A). The application of amicarbazone did not change this trend when applied, $100 \mu \mathrm{mol} \cdot \mathrm{m}^{-2} \cdot \mathrm{s}^{-1}$ blue light increased anthocyanin production, although overall concentration was reduced (Fig. 6B). This indicates that while photosynthesis may impact the degree to which blue light stimulates anthocyanin production, blue light alone is sufficient to induce anthocyanin synthesis.

For dark-grown seedlings, the addition of $100 \mu \mathrm{mol} \cdot \mathrm{m}^{-2} \cdot \mathrm{s}^{-1}$ blue light led to an increase in anthocyanin content compared with all other LED treatments (Fig. 6C) Similar to other treatments, when amicarbazone was applied to dark-grown seedlings, only $100 \mu \mathrm{mol} \cdot \mathrm{m}^{-2} \cdot \mathrm{s}^{-1}$ treatments accumulated anthocyanins in larger quantities (Fig. 6D). These results indicate that 100 $\mu \mathrm{mol} \cdot \mathrm{m}^{-2} \cdot \mathrm{s}^{-1}$ of blue light is necessary for the response to occur, and the addition of amicarbazone does not eliminate or reduce the response, as was observed in experiments with increasing red light.

\section{Discussion}

The objectives of this research were to determine artificial light conditions capable of inducing anthocyanin synthesis in rough bluegrass to evaluate the suitability of this turfgrass as a source of anthocyanin. Using high-intensity white light, rough bluegrass was able to increase anthocyanin content upwards of $0.06 \% \mathrm{FW}$, or $64 \mathrm{mg} / 100 \mathrm{~g} \mathrm{FW}$ (0.24\% dry weight (DW), or $243 \mathrm{mg} / 100 \mathrm{~g}$ DW). Previous research has shown that cyanidin-3-malonylglucoside is the primary anthocyanin produced by rough bluegrass under field conditions, and results here show that this is also true under high-intensity white light treatment (Fossen et al., 2002). For fruits and vegetables, anthocyanin content has been shown to range from $0.1 \%$ to $1 \%$ of DW (Delgado-Vargas et al., 2000). Our data therefore show that the anthocyanin content of rough bluegrass after high-light treatment is comparable to many common fruits and vegetables; particularly red leaf lettuce, where cyanidin-3-malonylglucoside is also the primary anthocyanin produced (Delgado-Vargas et al., 2000; Giusti and Wrolstad, 2001; Wu et al., 2006).

A major advantage of using turfgrass, e.g., rough bluegrass, for anthocyanin production is the ability to harvest leaves containing anthocyanin numerous times throughout a single growing season. Results from experiment 1 show that, rough bluegrass plants maintain the ability to synthesize large quantities of anthocyanin over time, even after aggressive harvesting. A conservative estimate of yield from one harvest, based on the amount of tissue harvested from experiment 1 in this study, would be $6 \mathrm{Mg} \cdot \mathrm{ha}^{-1} \mathrm{FW}$. Because of the aggressive growth of this species, it is reasonable to assume anthocyanin containing leaves could be harvested once per month under a moderate input management system if the methods described were used in an indoor vertical farm. Using these figures, we calculate that $\approx 72 \mathrm{Mg} \cdot \mathrm{ha}^{-1}$ FW extractable tissue could be produced annually, with an estimated anthocyanin yield of $45 \mathrm{~kg}$. Furthermore, since anthocyanin concentrations of $90 \mathrm{mg} / 100 \mathrm{~g} \mathrm{FW}$ were observed after high-light treatment of rough bluegrass (Table 1), potential anthocyanin yields of up to $65 \mathrm{~kg}$ per year may be possible.

Blackberry, blueberry, and grape generally produce greater concentrations of anthocyanin compared with rough bluegrass on average. However, relatively low fruit yield (compared with the mass of turfgrass tissue that could be harvested) ultimately results in less anthocyanin per hectare in the same time frame (de Pascual-Teresa and SanchezBallesta, 2008; Giusti and Wrolstad, 2001; USDA, 2015). For example, on average, blackberry may yield $\approx 20 \mathrm{~kg}$ anthocyanin per year, blueberry $18 \mathrm{~kg}$, and grape $66 \mathrm{~kg}$ relative to the potential $45-65 \mathrm{~kg}$ from rough bluegrass (de Pascual-Teresa and SanchezBallesta, 2008; Giusti and Wrolstad, 2001; USDA, 2015). Some tropical monocots, particularly palm trees such as Euterpe species, may also produce greater quantities and more diverse anthocyanins compared with rough 


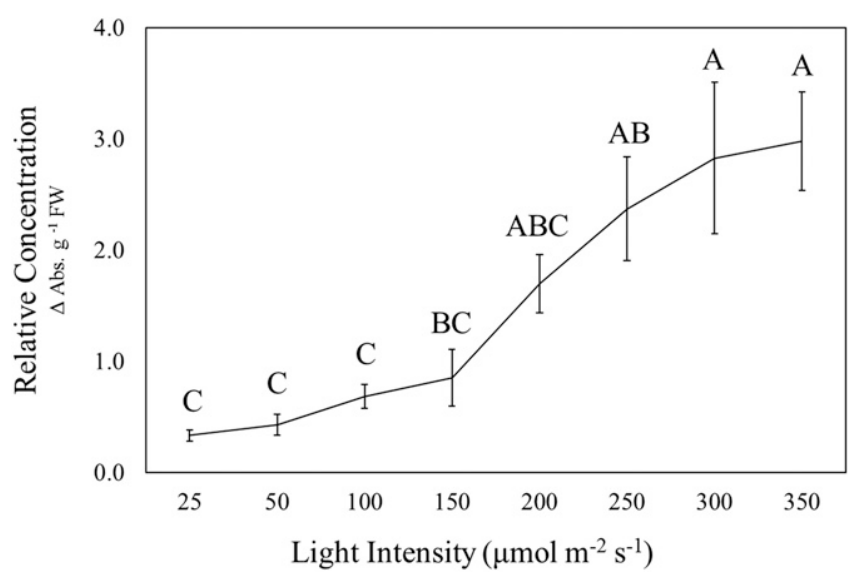

Fig. 3. Relative anthocyanin concentration of light-grown rough bluegrass seedlings treated with blue light-emitting diode light of increasing intensity. Plants were treated using the following light intensities: $25,50,100,150,200,250,300$, or $350 \mu \mathrm{mol} \cdot \mathrm{m}^{-2} \cdot \mathrm{s}^{-1}$. Relative anthocyanin concentration $=$ $\left(\mathrm{Abs}_{530}-0.25 \mathrm{Abs}_{657}\right) / \mathrm{g}$ fresh weight. Error bars represent treatment SE, and letters represent mean separation using Tukey's honest significant difference $(\mathrm{n}=3)$. Different letters indicate a significant statistical difference $(P=0.05)$.
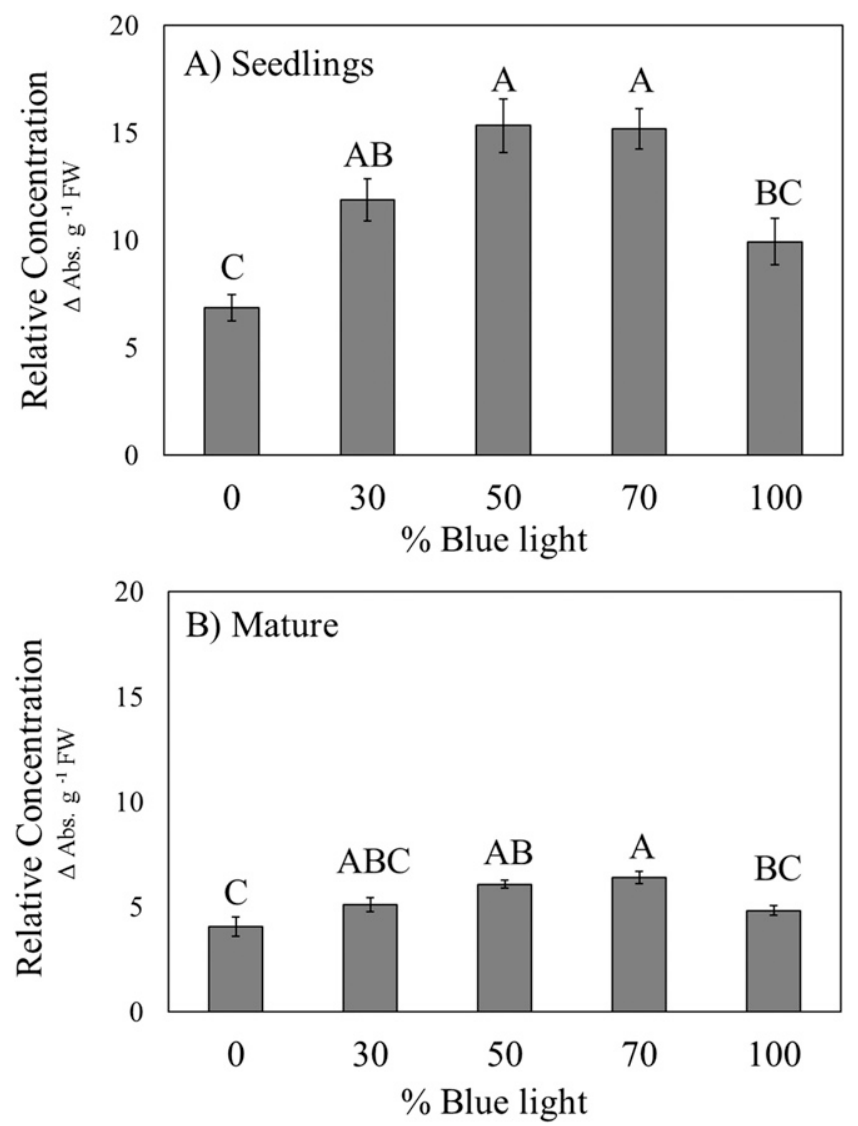

Fig. 4. Relative anthocyanin concentration of (A) light-grown seedlings and (B) mature (3-month old) rough bluegrass plants. Plants were treated with $200 \mu \mathrm{mol} \cdot \mathrm{m}^{-2} \cdot \mathrm{s}^{-1}$ of light-emitting diode light consisting of the following blue/red distributions: $0 \%$ blue ( $100 \%$ red), $30 \%$ blue ( $70 \%$ red), $50 \%$ blue $(50 \%$ red), $70 \%$ blue $\left(30 \%\right.$ red), or $100 \%$ blue $\left(0 \%\right.$ red). Relative anthocyanin concentration $=\left(\mathrm{Abs}_{530}-0.25 \mathrm{Abs}_{657}\right) / \mathrm{g}$ fresh weight. Error bars represent treatment SE, and letters represent mean separation using Tukey's honest significant difference $(\mathrm{n}=3)$. Different letters indicate a significant statistical difference $(P=0.05)$.

bluegrass (Del Pozo-Insfran et al., 2004). However, these palm trees only grow in very specific environments, they produce limited quantities of anthocyanin containing fruit, and only produce anthocyanins in a small portion of the plant (i.e., the fruit). anthocyanins could be used to meet industryspecific needs. Red leaf lettuce has been demonstrated to produce a complement of anthocyanins similar to that of bluegrass (i.e., cyanidin-3-malonylglucoside), but yield data for this species is lacking; although the few published reports indicate that anthocyanin levels are substantially lower than what was found in rough bluegrass $(2.2 \mathrm{mg} / 100 \mathrm{~g} \mathrm{FW}$ from lettuce vs. $64 \mathrm{mg} / 100 \mathrm{~g} \mathrm{FW}$ from rough bluegrass) from our study (Wu et al., 2006).

In addition, other perennial grasses may also have the potential to serve as anthocyanin production systems; including varieties of pigmented ornamental grasses (Pennisetum setaceum, Panicum virgatum, Miscanthus sinensis, etc.). Currently, however, data regarding anthocyanin yield in grass species is limited. Interestingly, red varieties of switchgrass (Panicum virgatum) have been shown to produce anthocyanins in quantities ranging from 60 to $200 \mathrm{mg} / 100 \mathrm{~g} \mathrm{FW}$ indicating that this grass may also serve as a potential source of anthocyanin (Boldt, 2013).

Blue light is necessary and sufficient to increase anthocyanin synthesis in rough bluegrass. Although red light is not required for anthocyanin synthesis in this species, treatment with blue and red light increased anthocyanin accumulation compared with blue light alone and exhibited a coaction response. However, the results of experiment 4 (Fig. 4) showed no statistical difference in anthocyanin production between plants treated with $100 \%$ blue or $100 \%$ red light, and this may be primarily the result of variability in "resting levels" of anthocyanins present in plants before LED treatments. Interestingly, these results indicate that growth conditions of rough bluegrass before light treatment (e.g., light conditions, temperature, water status, nitrogen availability, etc.) can impact light-induced anthocyanin production.

Combined treatment with blue and red light also decreased the threshold of blue light needed for anthocyanin synthesis to occur in experiments 4 and 5 . When $50 \%$ $\left(100 \mu \mathrm{mol} \cdot \mathrm{m}^{-2} \cdot \mathrm{s}^{-1}\right.$ blue light $)$ and $70 \%(140$ $\mu \mathrm{mol} \cdot \mathrm{m}^{-2} \cdot \mathrm{s}^{-1}$ blue light) blue light treatments were applied (i.e., a total of $200 \mu \mathrm{mol} \cdot \mathrm{m}^{-2} \cdot \mathrm{s}^{-1}$ combined blue and red light), there was an evident increase in anthocyanin content compared with $100 \%$ blue light (Fig. 4). Both of these treatments induced anthocyanin synthesis at quantities of blue light that were lower than what was shown to be required from our dose response experiment (Fig. 3-between 150 and $250 \mu \mathrm{mol} \cdot \mathrm{m}^{-2} \cdot \mathrm{s}^{-1}$ ). These data show that red light modulates the blue light threshold required to induce anthocyanin synthesis. Previous research suggests that this coaction effect could be mediated through phytochrome; however, our data suggest that the red light-induced modulation is primarily through photosynthesis (Kumar Das et al., 2011; Oh et al., 2014; Schneider and Stimson, 1971).

As this increase in anthocyanin content was saturated by the addition of amicarbazone in experiment 5, it is likely that the increase in accumulation observed when red light and blue light are applied together 
Light grown
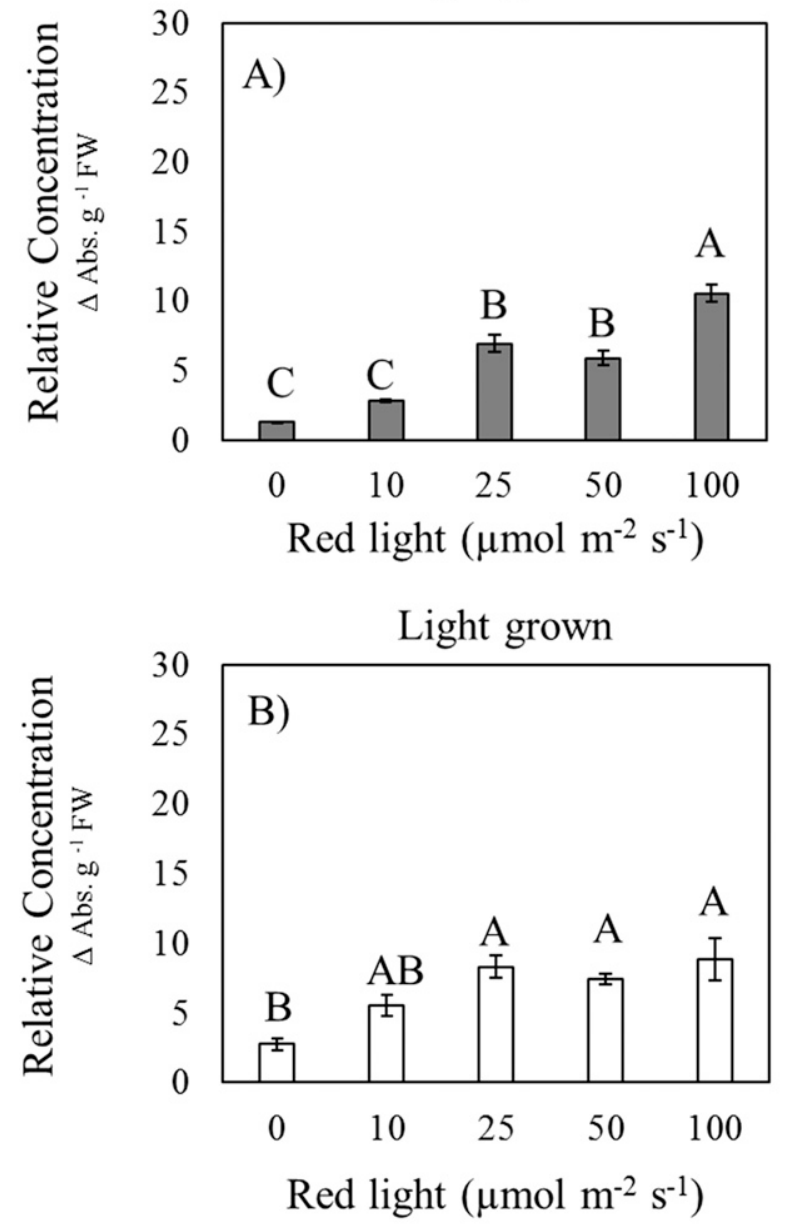

Dark grown
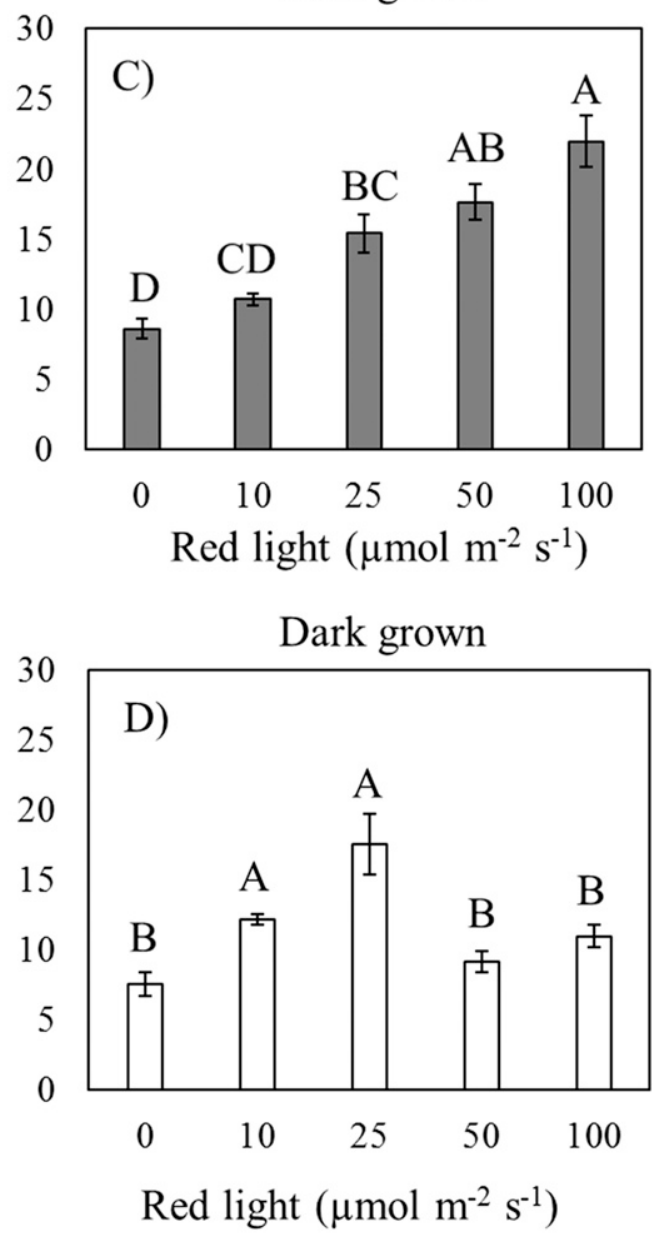

\section{Without AMI}

\section{With AMI}

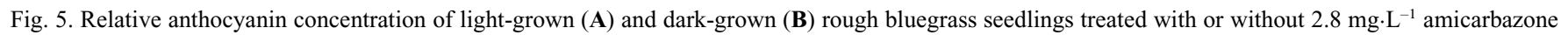
(AMI), and exposed to the following LED light treatments: $170 \mu \mathrm{mol} \cdot \mathrm{m}^{-2} \cdot \mathrm{s}^{-1}$ blue light plus $0,10,25,50$, or $100 \mu \mathrm{mol} \cdot \mathrm{m}^{-2} \cdot \mathrm{s}^{-1}$ or red light. Relative anthocyanin concentration $=\left(\mathrm{Abs}_{530}-0.25 \mathrm{Abs}_{657}\right) / \mathrm{g}$ fresh weight. Error bars represent treatment SE, and letters represent mean separation using Tukey's honest significant difference $(\mathrm{n}=3)$. Different letters indicate a significant statistical difference $(P=0.05)$.

(Figs. 5 and 6) is due to photosynthetic regulation. Loss of anthocyanin synthesis after application of diuron (DCMU-a PSII inhibitor related to amicarbazone) has been previously shown in Arabidopsis, petunia, and maize (Jeong et al., 2010; Kumar Das et al., 2011; Schneider and Stimson, 1971; Weiss and Halevy, 1991). For Arabidopsis in particular, the redox state of the plastoquinone (PQ) pool has been shown to be a potential signal for anthocyanin synthesis; DCMU oxidizes the PQ pool and decreases anthocyanin content, whereas the inhibitor dibromothymoquinone reduces the PQ pool and does not change anthocyanin content (Jeong et al., 2010). For rough bluegrass, if treatments with red light were impacting anthocyanin synthesis through modulation of phytochrome signaling, increases in anthocyanin synthesis would be expected to saturate at lower light intensities, which was not seen here. Our results show that antho- cyanin content increases with increasing intensities of red light applied with constant blue light, indicating that a coaction response is acting primarily through photosynthetic and cryptochrome signaling.

Our data also suggest that dark-grown plants may also exhibit increased anthocyanin content compared with light-grown plants, although the statistical significance of this trend was not clear. Dark-grown seedlings, however, showed a relatively large decline in anthocyanin content when treated under $170 \mu \mathrm{mol} \cdot \mathrm{m}^{-2} \cdot \mathrm{s}^{-1}$ blue light in conjunction with simultaneous treatment with amicarbazone and either 50 or $100 \mu \mathrm{mol} \cdot \mathrm{m}^{-2} \cdot \mathrm{s}^{-1}$ of added red light (Fig. 5). Dark-grown plants are more susceptible to both light stress and inhibition of photosynthesis by amicarbazone due to immature photosystems. Generally, photosynthetically impaired tissues accumulate greater quantities of anthocyanin, and we hypothesize that the addition of amicarbazone to these light sensitive seedlings during excessive light treatment led to irreversible photodamage resulting in impairment of signaling (Boldt, 2013; Chalker-Scott, 1999).

In experiment 2, seedlings accumulated greater quantities of anthocyanin compared with mature plants, which may be due to differences in quantities of chlorophyll a and $\mathrm{b}$ present in immature plants that compete for similar wavelengths of light (Merzylak et al., 2008). The photosynthetic machinery of seedlings is not fully established, and may require increased photoprotection through the accumulation of anthocyanins (Boldt, 2013; Chalker-Scott, 1999). In addition, when the levels of anthocyanin in light-grown seedlings are compared across experiments, anthocyanins from plants treated under LED light never reached or exceeded levels of anthocyanins quantified in plants treated under highintensity metal halide lighting. 
Light grown
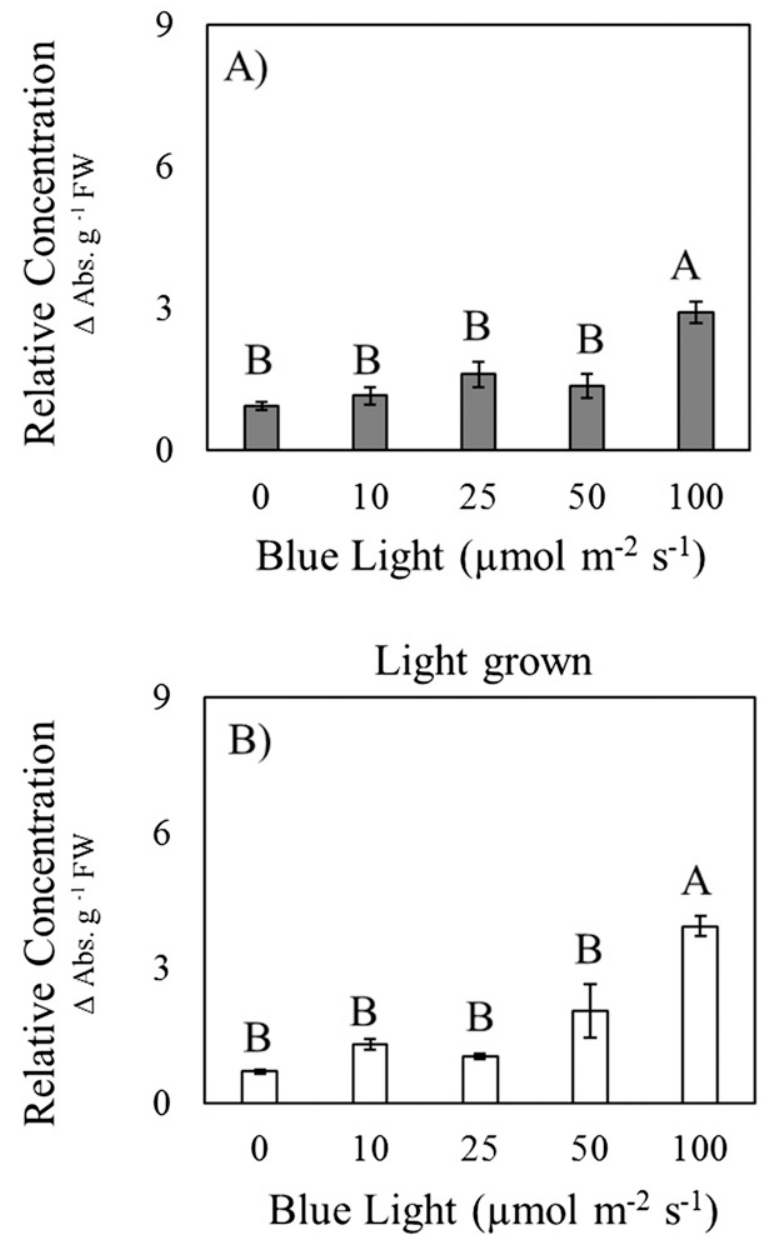

Dark grown

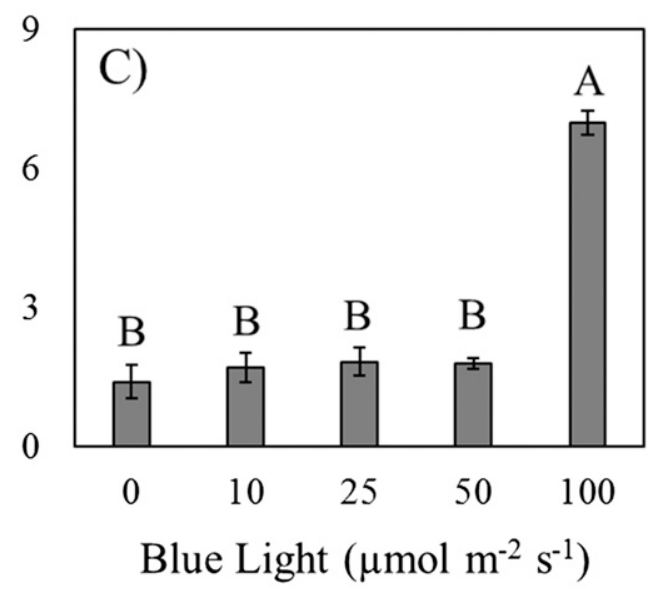

Dark grown

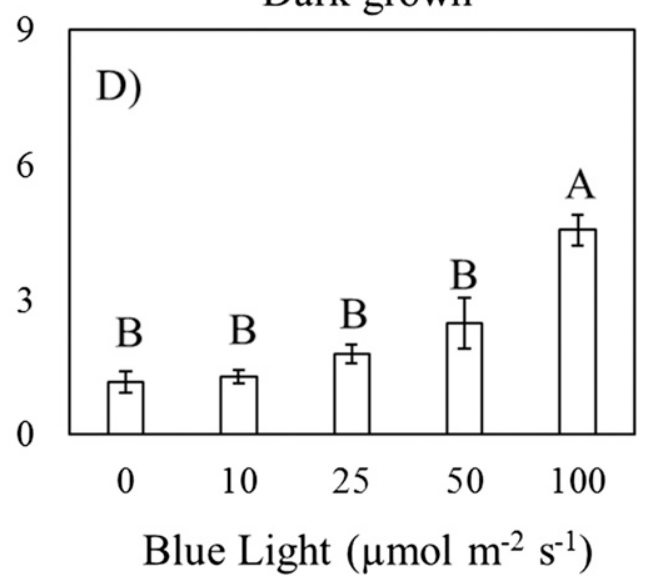

Without AMI

With AMI

Fig. 6. Relative anthocyanin concentration of (A) light-grown and (B) dark-grown rough bluegrass seedlings treated with or without $2.8 \mathrm{mg} \cdot \mathrm{L}^{-1}$ amicarbazone (AMI), and exposed to the following light-emitting diode light treatments: $170 \mu \mathrm{mol} \cdot \mathrm{m}^{2} \cdot \mathrm{s}^{-1}$ red light plus $0,10,25,50$, or $100 \mu \mathrm{mol} \cdot \mathrm{m}^{2} \cdot \mathrm{s}^{-1}$ or blue light. Relative anthocyanin concentration $=\left(\mathrm{Abs}_{530}-0.25 \mathrm{Abs}_{657}\right) / \mathrm{g}$ fresh weight. Error bars represent treatment sE, and letters represent mean separation using Tukey's honest significant difference $(\mathrm{n}=3)$. Different letters indicate a significant statistical difference $(P=0.05)$.

The decreased anthocyanin content of LED-treated rough bluegrass may result from the fact that plants grown under metal halide lamps were not only exposed to increased light intensity compared with LED treatments, but were also exposed to increased canopy temperatures and mild drought stress due to the heat generated by the lamps. It is well known that low temperature and drought stresses both have the ability to individually increase anthocyanin content in many plant species, including turfgrasses (Boldt et al., 2014; Chalker-Scott, 1999; Hughes et al., 2013; Mol et al., 1996). Although high temperatures are generally associated with degradation and loss of anthocyanin over time, rather than long-term increases in quantity; high temperatures are also known to be causative agents of photoinhibtion, and may therefore be potentially increasing short-term anthocyanin synthesis through photosynthesis
(Lin-Wang et al., 2011; Rabino and Mancinelli, 1986; Takahashi and Murata, 2008; Yamane et al., 2006).

Our results showed that high-intensity metal halide lighting significantly increased anthocyanin content, and that wavelengthspecific light treatments using LEDs may also increase the efficiency of anthocyanin synthesis. Currently, the use of LED systems to modulate anthocyanin production in turfgrasses would require greater upfront investment compared with traditional lighting. However, the upfront cost of the LED arrays would be largely offset over time due to decreased operating and maintenance costs, increasing the economic sustainability of anthocyanin production (Morrow, 2008). Similarly, the cost of LED lighting is estimated to decrease by 10 -fold every decade, making this a much more affordable alternative in the future (Haitz and Tsao, 2011; Stutte, 2015).
The research presented here has defined the optimal light conditions necessary for inducing large quantities of anthocyanins in rough bluegrass, and this data may also potentially be used in other perennial grass systems (e.g., other turfgrasses, ornamental grasses, or prairie grasses) to increase anthocyanin content. Our data show that white light at $1000 \mu \mathrm{mol} \cdot \mathrm{m}^{-2} \cdot \mathrm{s}^{-1}$ is sufficient for increasing anthocyanin content in rough bluegrass, and that treatment with $70 \%$ blue and $30 \%$ red light increases the efficiency of anthocyanin production compared with other wavelength applications. Our LED experiments showed that the application of 200 $\mu \mathrm{mol} \cdot \mathrm{m}^{-2} \cdot \mathrm{s}^{-1}$ of combined blue and red light significantly increased anthocyanin concentration relative to blue light alone; therefore, increasing the light intensity of this LED treatment may increase anthocyanin content beyond what was seen with white light 
treatment. Although, anthocyanin concentrations produced by rough bluegrass under these conditions may not be as high as currently used plant sources, the advantage of using a turfgrass is the ability to maximize anthocyanin yield over an entire growing season (through multiple harvests). Because of this, we calculate that the use of turfgrasses over an entire growing season could potentially increase anthocyanin yield by 2 -fold over currently used plant sources. These methods may help increase both the environmental and economic sustainability of anthocyanin extract production.

\section{Literature Cited}

Atkin, O.K., B. Botman, and H. Lambers. 1996. The causes of inherently slow growth in alpine plants: An analysis based on the underlying carbon economies of alpine and lowland Poa species. Funct. Ecol. 10(6):698-707.

Boldt, J.K. 2013. Foliar anthocyanins in coleus and ornamental grasses: Accumulation, localization, and function. Univ. of Minnesota, Minneapolis, MN, PhD. Diss.

Boldt, J.K., M.H. Meyer, and J.E. Erwin. 2014. Foliar anthocyanins: A horticultural review, p. 209-251. In: J. Janick (ed.). Hort. Rev. Wiley, New York, NY.

Chalker-Scott, L. 1999. Environmental significance of anthocyanins in plant stress responses. Photochem. Photobiol. 70(1):1-9.

Christians, N.E. 2011. Chapter 2: Introduction to the grasses, p. 9-31. In: N.E. Christians (ed.). Fundamentals of turfgrass management. 4th ed. Wiley, New York, NY.

Dayan, F.E., M.L.B. Trindade, and E.D. Velini. 2009. Amicarbazone, a new photosystem II inhibitor. Weed Sci. 57(6):579-583.

Delgado-Vargas, F., A.R. Jiménez, and O. ParedesLópez. 2000. Natural pigments: Carotenoids, anthocyanins, and betalains: Characteristics, biosynthesis, processing, and stability. Crit. Rev. Food Sci. Nutr. 40(3):173-289.

Del Pozo-Insfran, D., C.H. Brenes, and S.T. Taloctt. 2004. Phytochemical composition and pigment stability of acai (Euterpe oleracea Mart.). J. Agr. Food Chem. 52:1539-1545.

de Pascual-Teresa, S., C. Santos-Buelga, and J.C. Rivas-Gonzalo. 2002. LC-MS analysis of anthocyanins from purple corn cob. J. Sci. Food Agr. 82:1003-1006.

de Pascual-Teresa, S. and M.T. Sanchez-Ballesta. 2008. Anthocyanins: From plant to health. Phytochem. Rev. 7:281-299.

Deroles, S. 2009. Anthocyanin biosynthesis in plant cell cultures: A potential source of natural colourants, p. 107-168. In: K. Gould, K. Davies, and C. Winfield (eds.). Anthocyanins: Biosynthesis, functions, and applications. Springer-Verlag, New York, NY.

Downs, R.J. and H.W. Siegelman. 1963. Photocontrol of anthocyanin synthesis in Milo seedlings. Plant Physiol. 38(1):25-30.

Drumm, H. and H. Mohr. 1978. The mode of interaction between blue (UV) light photoreceptor and phytochrome in anthocyanin formation of the Sorghum seedling. Photochem. Photobiol. 27:241-248.

Folta, K.M. and S.D. Carvalho. 2015. Photoreceptors and control of horticultural plant traits. HortScience 50:1274-1280.

Fossen, T., R. Slimestad, D.O. Øvstedal, and Ø.M. Anderson. 2002. Anthocyanins of grasses. Biochem. Syst. Ecol. 30:855-864.
Fox, A.R., G.C. Soto, A.M. Jones, J.J. Casal, J.P. Muschietti, and M.A. Mazzella. 2012. Cry1 and GPA1 signaling genetically interact in hook opening and anthocyanin synthesis in Arabidopsis. Plant Mol. Biol. 20:315-324.

Galvão, V.C. and C. Frankhauser. 2015. Sensing the light environment in plants: Photoreceptors and early signaling steps. Curr. Opin. Neurobiol. 34:46-53.

Giusti, M. and R.E. Wrolstad. 2001. Characterization and measurement of anthocyanins by UVvisible spectroscopy. Curr. Protoc. Food Anal. Chem. 2:1-13.

Haitz, R. and J.Y. Tsao. 2011. Solid-state lighting: 'The case' 10 years after and future prospects. Phys. Status Solidi. 1:17-29.

Hao, S., J. Wu, Y. Huang, and J. Lin. 2006. Natural dyes as photosensitizers for dye-sensitized solar cell. Sol. Energy 80:209-214.

$\mathrm{He}$, J. and M. Giusti. 2010. Anthocyanin: Natural colorants with health-promoting properties. Annu. Rev. Food Sci. Technol. 1:163-187.

Hong, G., W. Hu, J. Li, Z. Chen, and L. Wang. 2009. Increased accumulation of artemisinin and anthocyanins in Artemisia annua expressing Arabidopsis blue light receptor CRY1. Plant Mol. Biol. Rpt. 27:334-341.

Hughes, N.M., C.B. Morley, and W.K. Smith. 2007. Coordination of anthocyanin decline and photosynthetic maturation in juvenile leaves of three deciduous tree species. New Phytol. 175:675-685.

Hughes, N.M., K.L. Carpenter, and J.G. Cannon. 2013. Estimating contribution of anthocyanin pigments to osmotic adjustment during leaf reddening. J. Plant Physiol. 170:230-233.

Hurley, R. 2010. Rough bluegrass (Poa trivialis L.), p. 67-73. In: M.D. Casler and R.R. Duncan (eds.). Turfgrass biology, genetics, and breeding. Wiley, New York, NY.

Jeong, S., P. Kumar Das, S.C. Jeoung, J. Song, H. K. Lee, Y. Kim, W.J. Kim, Y.I. Park, S. Yoo, S. Choi, G. Choi, and Y. Park. 2010. Ethylene suppression of sugar-induced anthocyanin pigmentation in Arabidopsis. Plant Physiol. 154:1514-1531

Kadomura-Isikawa, Y., K. Miyawaki, S. Noji, and A. Takahashi. 2013. Phototropin 2 is involved in blue light-induced anthocyanin accumulation in Fragaria x ananassa fruits. J. Plant Res. 126:847-857.

Kerckhoffs, L.H.J. and R.E. Kendrick. 1997. Photocontrol of anthocyanin biosynthesis in tomato. J. Plant Res. 110:141-149.

Krans, J.V. and J.B. Beard. 1980. The effects of stage of seedling development on selected physiological and morphology parameters in Kentucky bluegrass and red fescue, p. 89-95. Proc. of the Third Intl. Turfgrass Res. Conf. Amer. Soc. of Agron., Crop Sci. Soc. of Amer., Soil Sci. Soc. of Amer., and the Intl. Turfgrass Soc. Kumar Das, P., B. Geul, S. Choi, S. Yoo, and Y. Park. 2011. Photosynthesis-dependent anthocyanin pigmentation in Arabidopsis. Plant Signal. Behav. 6(1):23-25.

Landschoot, P.J. and D.V. Waddington. 1987. Response of turfgrass to various nitrogen sources. Soil Sci. Soc. Amer. J. 51:225-230.

Lange, H., W. Shiropshire, and H. Mohr. 1971. An analysis of phytochrome-mediated anthocyanin synthesis. Plant Physiol. 47:649-655.

Lin-Wang, K., D. Micheletti, J. Palmer, R. Voltz, L. Lozano, R. Espley, R.P. Hellens, D. Chagne, D.D. Rowan, M.A. Troggio, I. Iglesias, and A. C. Allan. 2011. High temperature reduces apple fruit color via modulation of the anthocyanin regulatory network. Plant Cell Environ. 34:1176-1190.
Mancinelli, A.L. 1985. Light-dependent anthocyanin synthesis: A model system for the study of plant photomorphogenesis. Bot. Rev. 51 (1):107-157.

Mancinelli, A.L., C.H. Yang, I. Rabino, and K.M. Kuzmanoff. 1976. Photocontrol of anthocyanin synthesis: V. Further evidence against the involvement of photosynthesis in high irradiance reaction anthocyanin synthesis of young seedlings. Plant Physiol. 58:241-217.

Mancinelli, A.L. and I. Rabino. 1978. The "High Irradiance Responses" of plant photomorphogenesis. Bot. Rev. 44(2):129-180.

Mansour, R., B. Ezzili, and M. Farouk. 2013. Dyeing properties of wool fabrics dyes with Vitis vinifera L. (Black Grenache) leaves extract. Fibers Polym. 14(5):786-792.

Merzylak, M.N., O.B. Chivkunova, A.E. Solovchenko, and K.R. Naqvi. 2008. Light absorption by anthocyanins in juvenile, stressed, and senescing leaves. J. Expt. Bot. 59(14):3903-3911.

Mohr, H. and H. Drumm-Herrel. 1983. Coaction between phytochrome and blue/UV light in anthocyanin synthesis in seedlings. Physiol. Plant. 58:408-414.

Mol, J., G. Jenkins, E. Schäfer, D. Weiss, and V. Walbot. 1996. Signal perception, transduction, and gene expression involved in anthocyanin biosynthesis. Crit. Rev. Plant Sci. 15(5-6): 525-557.

Morrow, R.C. 2008. LED lighting in horticulture. HortScience 43:1947-1950.

Nangle, E.J., D.S. Gardner, J.D. Metzger, L. RodriquezSaona, M.M. Giusti, T.K. Danneberger, and D.P. Petrella. 2015. Pigment changes in coolseason turfgrasses in response to ultravioletB light. Agron. J. 107(1):41-50.

Neff, M.M. and J. Chory. 1998. Genetic interactions between phytochrome A, phytochrome $\mathrm{B}$, and cryptochrome 1 during Arabidopsis development. Plant Physiol. 118:27-36.

Oh, S., S.N. Warnasooriya, and B.L. Montgomery. 2014. Mesophyll-localized phytochromes gate stress- and light-inducible anthocyanin accumulation in Arabidopsis thaliana. Plant Signal. Behav. 9:1-9.

Poppe, C., U. Sweere, H. Drumm-Herrel, and E. Schäfer. 1998. The blue light receptor cryptochrome 1 can interact independently of phytochrome A and B in Arabidopsis thaliana. Plant J. 16(4):466-471.

Rabino, I. and A.L. Mancinelli. 1986. Light, temperature, and anthocyanin production. Plant Physiol. 81:922-924.

Rabino, I., A.L. Mancinelli, and K.M. Kuzmanoff. 1977. Photocontrol of anthocyanin synthesis: VI. Spectral sensitivity, irradiance dependence, and reciprocity relationship. Plant Physiol. 59:569-573.

Schneider, M.J. and W.R. Stimson. 1971. Contribution of photosynthesis and phytochrome to the formation of anthocyanin in turnip seedlings. Plant Physiol. 48:312-315.

Stutte, G.W. 2015. Commercial transition to LEDs: A pathway to high-value products. HortScience 50:1297-1300.

Takahashi, S. and N. Murata. 2008. How do environmental stresses accelerate photoinhibtion? Trends Plant Sci. 13(4):178-182.

U.S. Department of Agriculture. 2015. Noncitrus fruits and nuts 2014 summary. US. Dept. of Agr., Washington, DC.

Vandenbussche, F., Y. Habricot, A.S. Condiff, R. Maldiney, D. Van Der Straeten, and M. Ahmad. 2007. HY5 is a point of convergence between cryptochrome and cytokinin signaling pathways in Arabidopsis thaliana. The Plant J. 49:428-441. 
Vyas, P., I. Haque, and M. Kumar. 2014. Photocontrol of differential gene expression and alterations in foliar anthocyanin accumulation: A comparative study using red and green forma Ocimum tenuiflorum. Acta Physiol. Plant. 36:2091-2102.

Wade, H.K., T.N. Bibikova, W.J. Valentine, and G.I. Jenkins. 2001. Interactions within a network of phytochrome, cryptochrome and UV-B phototransduction pathways regulate chalcone synthase gene expression in Arabidopsis leaf tissue. Plant J. 25(6):675-685.

Weiss, D. and A.H. Halevy. 1991. The role of light reactions in the regulation of anthocyanin synthesis in Petunia corollas. Physiol. Plant. 81:127-133.
Wellburn, A.R. 1994. The spectral determination of chlorophylls a and $\mathrm{b}$, as well as total carotenoids, using various solvents with spectrophotometers of different resolution. J. Plant Physiol. 144:307-313.

Wongcharee, K., V. Meeyoo, and S. Chavadej. 2007. Dye-sensitized solar cell using natural dyes extracted from rosella and blue pea flowers. Sol. Energy Mater. Sol. Cells 91:566-571.

Wrolstad, R.E. and C.A. Culver. 2012. Alternatives to those artificial FD\&C food colorants. Annu. Rev. Food Sci. 3:59-77.

Wu, X., G.R. Beecher, J.M. Holden, D.B. Hautowitz, S.E. Gebhardt, and R.L. Prior. 2006. Concentrations of anthocyanins in common foods consumed in the United States and estimation of normal consumption. J. Agr. Food Chem. 54: 4069-4075.

Yamamoto, Y. and R. Mizuguchi. 1982. Selection of a high and stable pigment-producing strain in cultured Euphorbia millii cells. Theor. Appl. Genet. 61:113-116.

Yamane, T., S. Tae Jeong, N. Goto-Yamamoto, Y. Koshita, and S. Kobayashi. 2006. Effects of temperature on anthocyanin biosynthesis in grape berry skins. Amer. J. Enol. Viticult. 57(1):54-59.

Younger, V.B. 1969. Physiology of growth and development, p. 187-216. In: A.A. Hanson and F.V. Juska (eds.). Turfgrass Science. Amer. Soc. of Agron. Madison, WI. 